\title{
Characteristics and Generation of Household Hazardous Waste (HHW) in Semarang City Indonesia
}

\author{
Elanda Fikri ${ }^{1,2 *}$, Purwanto Purwanto ${ }^{2,3}$ and Henna Rya Sunoko ${ }^{2,4}$ \\ ${ }^{1}$ Department of Environmental Health, Bandung Health Polytechnic, Cimahi Utara, Bandung, Indonesia \\ ${ }^{2}$ Doctoral Program of Environmental Science, School of Postgraduate Studies, Univers itas Diponegoro, Semarang, Indonesia \\ ${ }^{3}$ Department of Chemical Engineering, Faculty of Engineering, Universitas Diponegoro, Semarang, Indonesia \\ ${ }^{4}$ Faculty of Medicine, Universitas Diponegoro, Semarang, Indonesia
}

\begin{abstract}
Most of Household Hazardous Waste (HHW) is currently mixed with domestics waste. So that, it can impact human health and environmental quality. One important aspect in the management strategy is to determine the quantity generated and characteristics of HHW. The method used to determine the characteristics HHW refers to SNI 19-2454-2002, while the HHW generation refers to the SNI 19-36941994 calculated based on weight and volume. Research was conducted in four districts of Semarang. The samples used in this study were 400 families calculated based on the proportion of Slovin Formula. The characteristic of HHW in Semarang City is mainly infectious (79\%), then poisonous (13\%), combustible $(6 \%)$ and corrosive materials $(2 \%)$. The quantity HHW generated is $0.01 \mathrm{~kg} /$ person/day equivalent with $5.1 \%$ of municipal solid waste (MSW) in Semarang (linear equations : $y=1,278 x+82,00$ (volume), $\mathrm{y}=0,216 \mathrm{x}+13,89$ (weight).
\end{abstract}

\section{Introduction}

Generally, the people in the city $(85,3 \%)$ mix all components of household waste, included HHW. Many people do not know that household activities can produce dangerous waste and endanger health and surrounding environment [1-2]. Although the existence household hazardous waste in the waste appearance from city people is relatively small, but with the increasing population, the amount of waste generated will also increase.

The impact of HHW is accumulated in the water and soil is an annual. For example, research conducted by Tuthill et al [3] and Ololade et al [4] the sample shows result containing $\mathrm{Pb}, \mathrm{Ni}, \mathrm{Cd}$ and also the increase of physic parameter concentration and chemical such as $\mathrm{pH}$, turbidity, conductivity and phosphate [3-4]. Considering the potential of the impact of HHW, it would require proper management. One aspect that is important as a first step draw up guidelines and HHW management strategy is to determine the characteristics and HHW generation.

\section{Material and methods}

\subsection{Research sites}

The study was conducted in the Semarang City (Indonesia), Semarang lies between $6^{\circ} 50^{\prime}-7^{\circ} 10^{\prime}$ of south latitude and line $109^{\circ} 35-110^{\circ} 50^{\prime}$ of east longitude. The west border is Kendal Regency, the east border is Demak Regency, the south border is Semarang
Regency, and the north is Java Ocean with the length of $13,6 \mathrm{Km}$.

\subsection{The sample of the research}

The number of minimum sample measurement for Semarang City was 400 family, divided into 109 family in Pedurungan Sub-District (high economic level), 129 family for West Semarang Sub-District (medium economic level), 77 family for North Semarang SubDistrict (low economic level), and 85 family for Banyumanik Sub-District (topography of high land zone) [5-7]. The measurement of generation HHW refers to SNI 19-3694-1994 (National Standard of Indonesia). The characteristic or composition of HTHW identification was based on SNI 19-2454-2002 attachment.

\subsection{Primary data collection}

\subsubsection{HHW generation}

HHW generation is based on Indonesian National Standard (SNI 19-3694-1994) and was conducted for 32 consecutive days for four districts in the Semarang City.

\subsubsection{HHW characteristics}

Sampling was done by the separation of organic waste and HHW. After the separation, followed by 
identification of characteristic/composition HHW based attachment Indonesian National Standard SNI 19-24542002.

\section{Results and discussion}

\subsection{HHW generation}

HHW generation in Semarang City is 0.01 $\mathrm{kg} /$ person/day $(5.1 \% \mathrm{MSW})$ or $0.0591 \mathrm{1} / \mathrm{person} /$ day (3.9\% MSW). Estimated HHW generation in 2014 reach 16,003 tons/day or $94,415 \mathrm{~m}^{3} /$ day. Projection result in the next 4 years (2019) is estimated to reach minimum 17.1 ton/day or $101 \mathrm{~m}^{3} /$ day. More over this trend will increase by 18.5 ton/day each year or $109.4 \mathrm{~m}^{3} /$ day in 2025 (linear equations : $y=1,278 x+82,00$ (volume), $y=0,216 x+13,89$ (weight) (Figure 1).

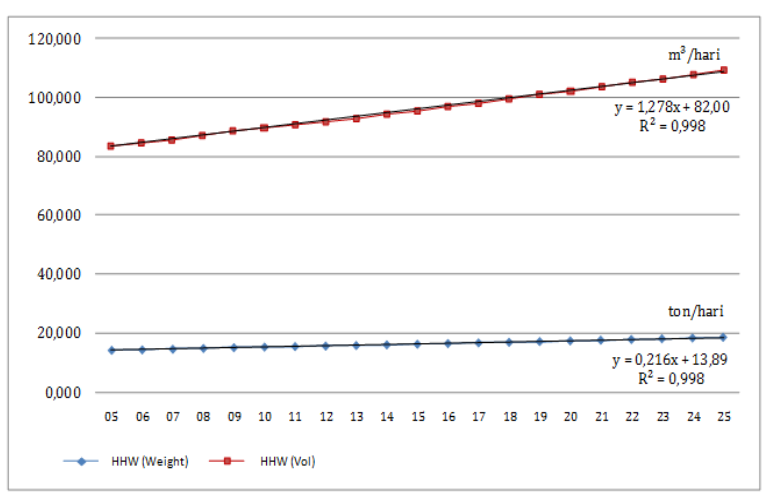

Fig. 1. HHW Generation in Semarang City

From the sampling result there should be a serious concern to manage infectious group of HHW. Until now, there is no stated regulation including in SNI 19-24542002. Revision is needed in that SNI. In this research, HHW infectious group was included in the analyses based on the effect on health (infection spreading) that would be caused and the degrading of environment quality. This background was supported by the categorization conducted by Delgado et al., and Jin et al., [8-9]. According to Delgado et al [8] classification HHW there are 8 categories, one of which is that it can cause an infection such as: rubber gloves, syringes, condoms, bandages and gauze bandages, while Jin et al confirm the statement "waste segregation at the source it self is extremely important as municipal solid waste turn hazardous when mixed with hazardous waste such as pain, dyes, batteries and human excreta". So it is clear that the addition of one (1) characteristics/category HHW as "infectious" is one that is relevant, both from a quantitative and health impacts and environmental degradation.

Based on the sampling results of the 400 families within 32 days in the city, HHW with the characteristics of "infectious" the most dominant and commonly found types of diapers, bandages, gauze, some condoms and plabot former infusion. The diversity of the characteristics of HHW in Pedurungan found in the

\subsection{HHW characteristics}

Characteristic of HHW in Semarang was divided into 4 types: corrosive, combustible, poisonous and infectious. Sampling results to identify the characteristics of HHW in Semarang city indicate that HHW generation: corrosive $(0.0002 \mathrm{~kg} /$ person/day), combustible $(0.0006$ $\mathrm{kg} /$ person/day), poisonous $(0.0018 \mathrm{~kg} /$ person/day) and infectious ( $0.0074 \mathrm{~kg} /$ person/day).

Based on descriptive analysis in Figure 2, the domination characteristic of HHW based on the measurement of weight scale was infectious group with $79 \%$, and then poisonous group $13 \%$, combustible $6 \%$, and the last corrosive with $2 \%$ percentage.

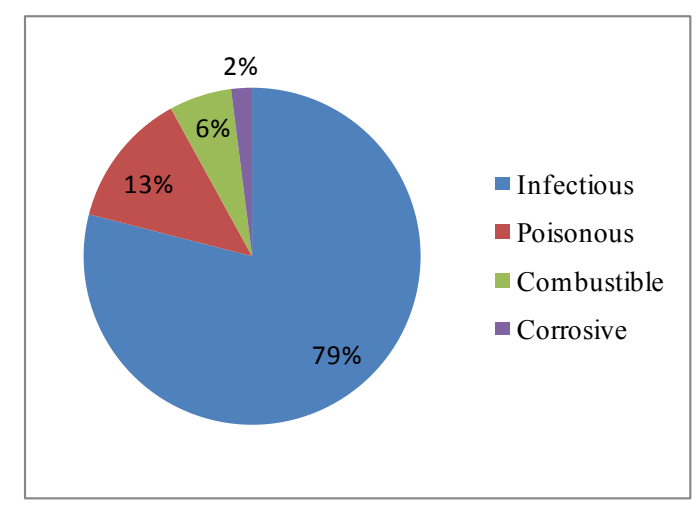

Fig. 2. Comparison of the characteristics of HHW

district which is a region on a sample group of economic strata.

Different characteristics HHW based economic strata, does not mean the same with different characteristics Based HHW topography. The statistical results using Kruskal-Walis test showed no differences in the characteristics HHW based topographic regions (p-value 0.442). So that the test results can be interpreted to have similar characteristics to HHW based topographic regions in Semarang.

\subsection{Comparisons with other countries}

Previous research found in seven (7) different countries, including: India, Vietnam, Switzerland, Mexico, Greece, the UK and Hungary. For example, research conducted by Lakshmikantha and Lakshminarasimaiah in the State of Karnataka (India) [10], which reported that the results of sampling HHW in the City of $0.005 \mathrm{~kg} /$ person/day (300 tons/day or $0.9 \% \mathrm{MSW}$ ). Results of another study, reported by Thanh et al [11] based on the results of the sampling in the Mekong (Vietnam) were reported in the city HHW generation is smaller, and only reaches $0.00053 \mathrm{~kg} /$ person/day $(0.2 \% \mathrm{MSW})$ [11]. Other studies have also reported that studies are not much different, as in Switzerland which reported its HHW generation of 2 $\mathrm{kg} / \mathrm{person} /$ year in 2001 with a percentage $(0.5 \%$ of MSW), which means lower than generation HHW in 
Semarang per year, which reached $3.65 \mathrm{~kg} /$ person/year with a percentage $(5.1 \% \mathrm{MSW})$.

Research conducted by Otoniel et al in Morelia (Mexico) shows the same thing also that generation HHW City Morelia (Mexico) is estimated to 7.1 tonnes/day with a percentage of $1.6 \%$ of the total domestic waste [12]. While in Semarang in 2014 is estimated to reach 16.0 tons/day HHW with a percentage of $5.1 \%$ of the total domestic waste.

Other studies have shown different results with this research. Research conducted by Zotos et al in Greece who reported HHW generation of 7,000 tons per year [13], further research reported by Otoniel et al on HHW generation in the UK amounted to 250,000 tons HHW / year with a percentage $0.9 \%$ HHW in MSW with the largest HHW category is aerosol (26\%), paint (17\%), oil
$(15 \%)$, batteries (14\%) and bleach (10\%). Different also reported from Hungary in 2002, there were 17,000 tons of HHW or about $0.7 \%$ of MSW [12].

Based on the comparison HHW generation in India, Vietnam, Switzerland, Mexico, Greece, the UK and Hungary has been described previously, indicating generation HHW in Semarang higher than in the country of India, Vietnam, Switzerland and Mexico, but is smaller when compared to the generation HHW in Greek, English and Hungarian. This indicates the diversity of generation HHW level in each country. In addition to the comparison of from 11 countries, there are few studies that reported on the contribution/percentage HHW in domestic waste, including:

Table 1. Comparison of contribution/percentage HHW with domestic waste

\begin{tabular}{|c|l|c|c|}
\hline No & \multicolumn{1}{|c|}{ Study } & $\begin{array}{c}\text { \% of } \\
\text { MSW }\end{array}$ & Reference \\
\hline 1 & Tehran & 10 & {$[14]$} \\
\hline 2 & Semarang, Indonesia (Weight Scale) & 5,7 & This study \\
\hline 3 & Massachussets, USA & 5,0 & {$[15]$} \\
\hline 4 & Semarang Indonesia (Volume Scale) & 3,9 & This study \\
\hline 5 & Mexicali & 3,7 & {$[8]$} \\
\hline 6 & Morelia, Meksiko & 1,6 & {$[12]$} \\
\hline 7 & Greenland & 1,2 & {$[8]$} \\
\hline 8 & Cuitzeo, Basin, Meksiko & 1,01 & {$[17]$} \\
\hline 9 & UK & 1 & {$[10]$} \\
\hline 10 & Karnataka, India & 0,9 & {$[11]$} \\
\hline 11 & Mekong Delta City, Vietnam & 0,2 & {$[18]$} \\
\hline 12 & Thesaloniki, Yunani & 0,06 & {$[19]$} \\
\hline 13 & Hangzhou, China & 0,05 & \\
\hline
\end{tabular}

Based on Table 1 shows that the percentage HHW in Semarang is similar to research done by Tuthill et al in Massachusetts, USA with a percentage of 5.7\% [3]. But the results of this study is lower to that of Ziaee et al in the city of Tehran that its HHW percentage reaches $10 \%$ of the domestic waste [14] [20].

\section{Conclusions}

1) Analysis by weight showed HHW generation reached $0.01 \mathrm{~kg} /$ person/day or $5.1 \%$ of total domestic waste (linear equations : $y=1,278 x+82,00$ (volume), $y=0,216 x+13,89$ (weight).

2) The characteristic of HHW in Semarang was consist of corrosive, combustible, poisonous, and infectious. The largest characteristic of HHW in Semarang is Infectious. Domination characteristic of HHW based on the measurement of weight scale was infectious group with $79 \%$, and then poisonous group $13 \%$, combustible $6 \%$, and the last corrosive with $2 \%$ percentage.

\section{Acknowledgements}

This study was financially supported by Lembaga Pengelola Dana Pendidikan (LPDP), Ministry of Finance, Indonesia scheme (Contract : PRJ598/LPDP/2014).

\section{References}

1. E. Fikri, Purwanto, R.S. Henna, Procedia Environmental Sciences. 23, 123 - 129, (2015)

2. E. Fikri, Purwanto, R.S. Henna, Int. J. Environment and Waste Management. 17(2), 146-157, (2016)

3. R.W. Tuthill, J.S. Edward, C. Willis, G.S. Moore, American Journal of Public Health (AJPH). 77, 304306, (1987)

4. I.A. Ololade, A. Adewunmi, A. Ologundudu, A. Adeleye, International Journal of Phisical Science. 4, 22-29, (2009)

5. C.G. Sevilla, A Research Primer, Quezon City Philippines: Rex Printing Company. Inc, (1990)

6. M.M. Rivera, and R.V. Rivera, Philippines: Katha Publishing, (2007)

7. T.P. Ryan, New Jersey: John Wiley \& Sons, Inc, (2013)

8. O.B. Delgado, S. Ojeda-Benitez, BL. Marquez, Journal Waste Management. 27, 792-801, (2007)

9. J. Jin, Z. Wang, S. Ran, Journal Waste Management. 26, 1045-1051, (2006)

10.H. Lakshmikantha, and N. Lakshminarasimaiah, Proceeding of The International Conference on Sustainable Solid Waste Management 5-7 September 2007, Chennai, India; 163-168, (2007)

11. N.P. Thanh, Y. Matsui, T. Fujiwara, Jounal of Environmental Management. 2307-2321, (2010) 
12. B.D. Otoniel, M.B. Liliana, P.G. Francelia, Waste Management. 28, 52-56, (2008)

13. G. Zotos, A. Karagiannidis, S. Zampetoglou, A. Malamakis, I.S. Antonopoulos, S. Kontogianni, G. Tchobanoglous, Journal Waste Management; 29,1686-1692, (2009)

14.S. Ziaee, G. Omrani, M.M.A. Agha, N. Mansouri, Advances in Environmental Biology. 6, 676-68, (2012)

15. E.J. Stanek, R.W. Tuthill, C. Willis, G.S. Moore, Archives of Environmental Health; 42, 84-86, (1987)

16. R. Eisted, and T.H. Christensen, Journal Waste Management. 31, 1461-1466, (2011)
17. S.J. Burnley, Journal Waste Management. 27, 1274 $1285,(2007)$

18. E. Papachristou, H. Hadjianghelou, E. Darakas, K. Alivanis, A. Belou, D. Ioannidou, E. Paraskevopoulou, K. Poulios, A. Koukourikou, N. Kosmidou, K. Sortikos, Journal Waste Management, 29.1158-1162, (2009).

19. Y. Zhuang, S.W. Wu, Y.L. Wang, W.X. Wu, Y.X. Chen, Journal Waste Management. 28, 2022-2030, (2008)

20.E. Fikri, Purwanto, R.S. Henna, Journal of Ecological Engineering. 18, (5), (2017) 